Supplement of Hydrol. Earth Syst. Sci., 24, 3289-3309, 2020

https://doi.org/10.5194/hess-24-3289-2020-supplement

(c) Author(s) 2020. This work is distributed under

the Creative Commons Attribution 4.0 License.

(c) (1)

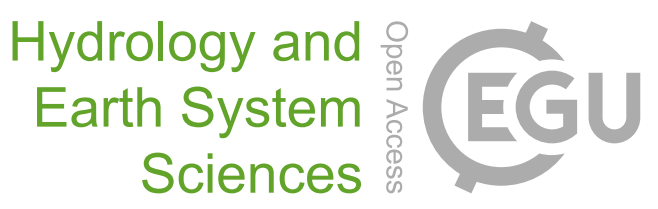

Supplement of

\title{
Comparing Bayesian and traditional end-member mixing approaches for hydrograph separation in a glacierized basin
}

Zhihua He et al.

Correspondence to: Zhihua He (zhwork3533@163.com)

The copyright of individual parts of the supplement might differ from the CC BY 4.0 License. 

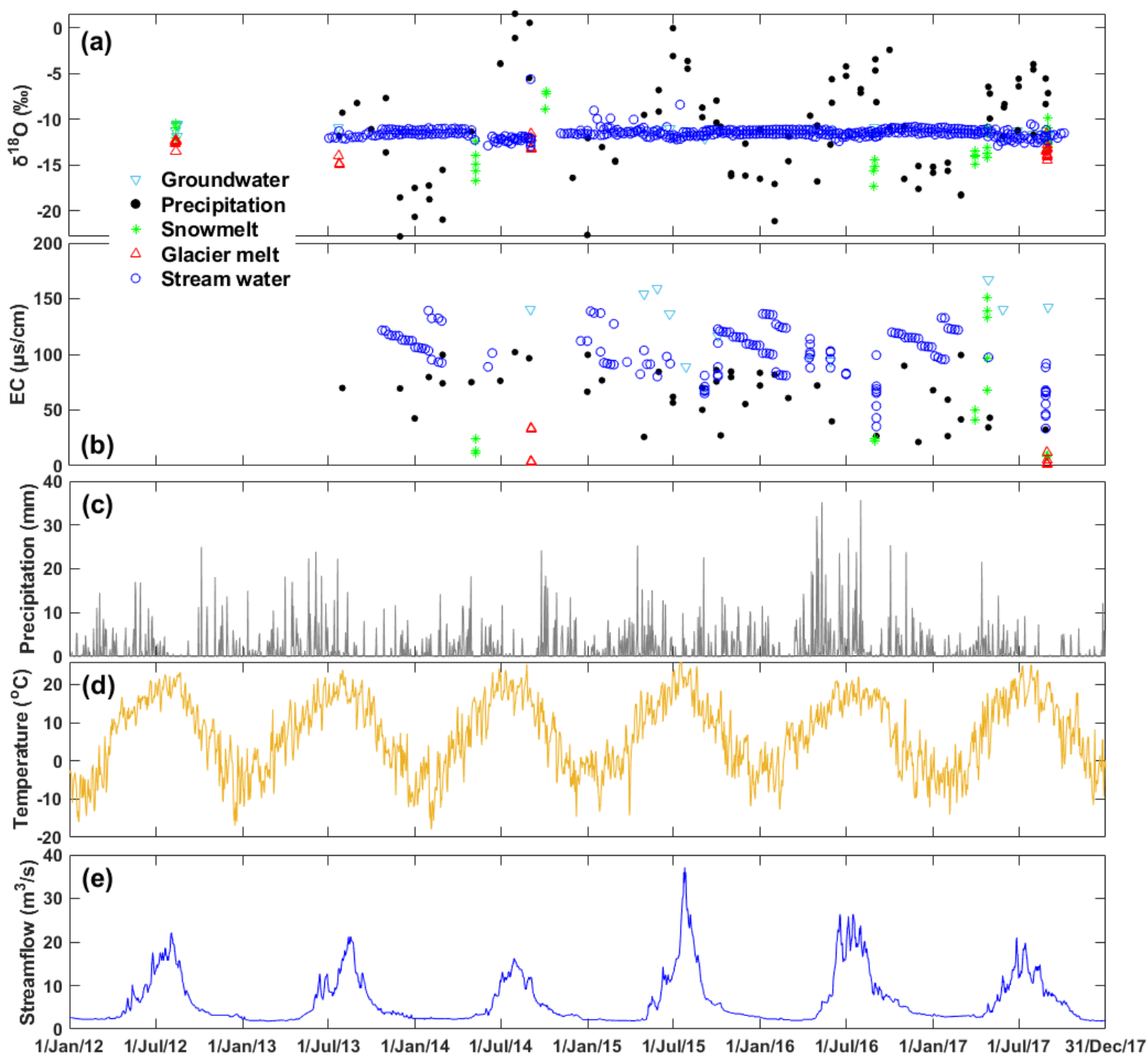

Figure S1. (a)-(b) Tracer signatures of water samples during the sample period of 2012-

3 2017;(c)-(d) Daily precipitation and temperature measured at the Baitik meteorological station in 2012-12017; (e) Daily streamflow measured at the Ala-Archa hydrologic station during 2012-2017. 